\title{
Influence of mitochondrial genome rearrangement on cucumber leaf carbon and nitrogen metabolism
}

\author{
Bożena Szal • Agata Jastrzębska • Marek Kulka Karolina Leśniak • \\ Anna Podgórska · Tiit Pärnik · Hiie Ivanova · Olav Keerberg • \\ Per Gardeström $\cdot$ Anna M. Rychter
}

Received: 30 March 2010/Accepted: 22 August 2010/Published online: 10 September 2010

(C) The Author(s) 2010. This article is published with open access at Springerlink.com

\begin{abstract}
The MSC16 cucumber (Cucumis sativus L.) mitochondrial mutant was used to study the effect of mitochondrial dysfunction and disturbed subcellular redox state on leaf day/night carbon and nitrogen metabolism. We have shown that the mitochondrial dysfunction in MSC16 plants had no effect on photosynthetic $\mathrm{CO}_{2}$ assimilation, but the concentration of soluble carbohydrates and starch was higher in leaves of MSC16 plants. Impaired mitochondrial respiratory chain activity was associated with the perturbation of mitochondrial TCA cycle manifested, e.g., by lowered decarboxylation rate. Mitochondrial dysfunction in MSC16 plants had different influence on leaf cell metabolism under dark or light conditions. In the dark, when the main mitochondrial function is the energy production, the altered activity of TCA cycle in mutated plants was connected with the accumulation of pyruvate and TCA cycle intermediates (citrate and 2-OG). In the light, when TCA activity is needed for synthesis of carbon skeletons required as the acceptors for $\mathrm{NH}_{4}^{+}$ assimilation, the concentration of pyruvate and TCA intermediates was tightly coupled with nitrate metabolism. Enhanced incorporation of ammonium group into amino
\end{abstract}

B. Szal ( $₫)$ · A. Jastrzębska · M. Kulka · K. Leśniak ·

A. Podgórska · A. M. Rychter

Institute of Experimental Plant Biology, University of Warsaw,

Miecznikowa 1, 02-096 Warsaw, Poland

e-mail: szal@biol.uw.edu.pl

T. Pärnik $\cdot$ H. Ivanova $\cdot$ O. Keerberg

Department of Plant Physiology,

Estonian University of Life Sciences, 76902 Harku, Estonia

P. Gardeström

Umea Plant Science Center, Umea University,

90187 Umea, Sweden acids structures in mutated plants has resulted in decreased concentration of organic acids and accumulation of Glu.

Keywords C/N metabolism - Cucumis - Mitochondrial mutant $\cdot$ TCA cycle

$\begin{array}{ll}\text { Abbreviations } \\ \text { AAT } & \text { Alanine aminotransferase } \\ \text { AOX } & \text { Alternative oxidase } \\ \text { BSA } & \text { Bovine serum albumin } \\ \text { CMS } & \text { Cytoplasmic male sterile } \\ \text { COX } & \text { Cytochrome } c \text { oxidase } \\ \text { CS } & \text { Citrate synthase } \\ \text { DABS } & \text { 4-(4-Dimethylaminophenylazo) } \\ & \text { benzenesulfonyl } \\ \text { ETC } & \text { Electron transport chain } \\ \text { Fru } & \text { Fructose } \\ \text { FW } & \text { Fresh weight } \\ \text { Glc } & \text { Glucose } \\ \text { GOGAT } & \text { Glutamine:2-oxoglutarate aminotransferase } \\ \text { GS } & \text { Glutamine synthetase } \\ \text { IDH } & \text { Isocitrate dehydrogenase } \\ \text { MDH } & \text { Malate dehydrogenase } \\ \text { MSC16 } & \text { Mosaic cucumber } \\ \text { mtETC } & \text { Mitochondrial electron transport chain } \\ \text { NR } & \text { Nitrate reductase } \\ 2-O G & \text { 2-Oxoglutarate } \\ \text { OGDC } & \text { Oxoglutarate dehydrogenase complex } \\ \text { PAR } & \text { Photosynthetically active radiation } \\ \text { PCA } & \text { Perchloric acid } \\ \text { PDC } & \text { Pyruvate dehydrogenase complex } \\ R & \text { Total decarboxylation in the light } \\ R \text { A } & \text { Total decarboxylation of primary } \\ & \text { photosynthates } \\ & \\ & \end{array}$




$\begin{array}{ll}R_{\mathrm{D}} & \begin{array}{l}\text { Respiration in the dark } \\ R_{\mathrm{P}}\end{array} \\ R_{\mathrm{PA}} & \begin{array}{l}\text { Photorespiratory decarboxylation in the light } \\ \text { Photorespiratory decarboxylation of primary } \\ \text { photosynthates }\end{array} \\ R_{\mathrm{PS}} & \begin{array}{l}\text { Photorespiratory decarboxylation of stored } \\ \text { photosynthates }\end{array} \\ R_{\mathrm{R}} & \begin{array}{l}\text { Respiratory decarboxylation in the light } \\ \text { Respiratory decarboxylation of primary } \\ R_{\mathrm{RA}}\end{array} \\ R_{\mathrm{RS}} & \begin{array}{l}\text { photosynthates } \\ \text { Respiratory decarboxylation of stored } \\ \text { photosynthates }\end{array} \\ R_{\mathrm{S}} & \begin{array}{l}\text { Total decarboxylation of stored } \\ \text { photosynthates }\end{array} \\ \text { RP-HPLC } & \begin{array}{l}\text { Reverse phase-high pressure liquid } \\ \text { chromatography }\end{array} \\ \text { Suc } & \begin{array}{l}\text { Sucrose } \\ \text { TCicarboxylic acid }\end{array} \\ \text { WT } & \text { Wild type }\end{array}$

\section{Introduction}

During the dark period, leaf mitochondrial functions are restricted mainly to producing the energy needed for growth, maintenance, and transport, and providing intermediates used for cellular biosynthesis. Storage sugars are degraded and the end-products of glycolysis, pyruvate and oxaloacetate/malate, are imported into mitochondria, where they are oxidized in the TCA cycle. The reducing equivalents $\left(\mathrm{NADH}\right.$ and $\mathrm{FADH}_{2}$ ) produced during mitochondrial substrate-oxidation are oxidized further by the mtETC to generate the proton gradient across the inner membrane, which is subsequently used for ATP production.

In illuminated $\mathrm{C} 3$ leaves the metabolic situation is different, with Gly produced in the photorespiratory pathway as the main substrate for the mtETC (Gardeström et al. 2002; Raghavendra and Padmasree 2003). A decrease in respiratory decarboxylations is generally observed in light versus darkness (Hurry et al. 2005), implying decreased TCA cycle activity. Operation of the TCA cycle in the light can be restricted due to inactivation of the mitochondrial pyruvate dehydrogenase complex (PDC) (Tovar-Méndez et al. 2003) and limitations in isocitrate dehydrogenase activities (Bykova et al. 2005). As a consequence, it is likely that a partial TCA cycle operates in the light (Hurry et al. 2005). In agreement with this, illuminated French bean leaves showed 27\% inactivation of PDC whereas flux through the TCA cycle was reduced by $95 \%$ (Tcherkez et al. 2005). In the light TCA activity is needed for synthesis of intermediates. In particular, 2-oxoglutarate (2-OG) is required as an acceptor for $\mathrm{NH}_{4}^{+}$in the GS-GOGAT pathway localized in the chloroplasts. It is possible for 2-OG to be withdrawn directly from the TCA cycle and exported to the cytosol via the di/tricarboxylate transporter (Picault et al. 2004; Noguchi and Yosida 2008). Alternatively, citrate can be exported and converted to $2-\mathrm{OG}$ in the cytosol by aconitase and NADP-isocitrate dehydrogenase (Lancien et al. 2000; Hurry et al. 2005). The proposal of an operation of a partial TCA cycle in the light is supported by the results from labeling experiments using ${ }^{13} \mathrm{C}$-pyruvate. The main labeled metabolites were Glu (corresponding to 2-OG) and citrate, whereas label in succinate and fumarate was very low (Tcherkez et al. 2005).

Mitochondrial metabolism is also essential for optimizing photosynthetic carbon fixation (Krömer 1995; Raghavendra and Padmasree 2003; Igamberdiev et al. 2006; Plaxton and Podestá 2006; Nunes-Nesi et al. 2008). Mitochondria facilitate the export of excess reductants from chloroplasts, prevent over-reduction of the photosynthetic ETC, and supply ATP for cytosolic sucrose synthesis. These unique functions of plant mitochondria are possible due to the presence of alternatives to the Complex I or cytochrome pathway, respiratory chain components, different bypasses of TCA cycle, and plant specific metabolite exchangers between mitochondria and the cytosol (Møller 2001; Picault et al. 2004; Plaxton and Podestá 2006; Rasmusson et al. 2008).

The MSC16 line of cucumber (Cucumis sativus L.), possessing rearrangements in the chondriome (Malepszy et al. 1996; Bartoszewski et al. 2004), manifests a mosaic phenotype and slower growth rate. Mitochondria of MSC16 plants have decreased capacity and activity of Complex I and internal rotenone-insensitive NADH dehydrogenase, but increased protein level of AOX (Juszczuk et al. 2007; Juszczuk and Rychter 2009). Lower Complex I activity in MSC16 plants is partially compensated by increased external NADH dehydrogenase activity (Juszczuk et al. 2007). The content of both adenylates and $\mathrm{NADP}(\mathrm{H})$ is decreased in mutant plants, and changes in energy and redox status affected mainly the chloroplastidial pools (Szal et al. 2008). Additionally, dysfunction of the mitochondrial respiratory chain in MSC16 was associated with great changes in the subcellular NADH/NAD ratios. The cytosolic pool was much more reduced, whereas the mitochondrial pool was more oxidized in comparison with WT (Szal et al. 2008).

Understanding of $\mathrm{C} / \mathrm{N}$ interactions has for decades been a major challenge in plant physiology and is especially important in an agronomic context. In the well-characterized CMSII tobacco plants, the lack of mitochondrial Complex I (Sabar et al. 2000) leads to modification of the foliar carbonnitrogen balance (Dutilleul et al. 2005). At the same time, in the CMSII mutant the content of adenylates is much higher than in WT indicating that the plants are not energy deficient (Szal et al. 2008). Herein we evaluate how the changes of cucumber leaf energy and redox status due to lower activity 
of Complex I in the MSC16 line influence leaf day/night carbon and nitrogen metabolism. We determined the concentration of sugars and TCA intermediates, and the activities/protein levels of TCA cycle enzymes, along with the concentrations of metabolites and activities of enzyme involved in primary $\mathrm{N}$ metabolism. We also measured the rates of photosynthesis and respiration using the plants grown at medium light intensity (similar to that used for measuring metabolite concentration) as our previous estimations of gas exchange were done using plants grown in high light intensity (Juszczuk et al. 2007).

\section{Materials and methods}

Plant material and growth conditions

MSC16 mutant seeds were supplied by the Department of Plant Genetics, Breeding and Biotechnology, Warsaw University of Life Sciences. Cucumber seeds (Cucumis sativus L. cv. Borszczagowski) of wild type (WT) or MSC16 mutant were germinated on moist filter paper and 3-day-old seedlings were transferred to boxes with complete Knop medium (Rychter and Mikulska 1990). The nutrient solution was supplemented daily, and changed completely every 4 days. Plants were grown with a 16-h photoperiod at $200 \mu \mathrm{mol}$ $\mathrm{m}^{-2} \mathrm{~s}^{-1}$ PAR (daylight and warm white 1:1, LF-40W, Piła, Poland), day/night temperature of $24 / 20^{\circ} \mathrm{C}$, and $60 / 70 \%$ relative humidity. Plants for the measurements of partitioning of fixed carbon into soluble sugars and starch and rates of decarboxylation components (results in Tables 1,2) were grown in soil. According to lowered growth rate of mutated line, mutants were grown longer; plants used in the experiments were at the same growth stage. The first or second leaf from WT or MSC16 plants with fully developed four leaves were collected for analysis after $6 \mathrm{~h}$ of illumination or $8 \mathrm{~h}$ into the night period.

\section{Isolation of mitochondria}

Organelles were isolated from 30 to $40 \mathrm{~g}$ of leaves, and purified using discontinuous Percoll gradients as described in Juszczuk et al. (2007). The mitochondrial fraction was collected from the $28 / 45 \%$ (v/v) Percoll interface, then washed in a medium containing $0.45 \mathrm{M}$ mannitol, $10 \mathrm{mM}$ phosphate buffer, $\mathrm{pH} 7.2,1 \mathrm{mM}$ EDTA, and $0.5 \%(\mathrm{w} / \mathrm{v})$ BSA.

Measurement of metabolite concentrations

For sugar extraction, approx. $1 \mathrm{~g} \mathrm{FW}$ of tissue was rinsed, blotted, weighed, and ground in a precooled mortar with $3 \mathrm{ml}$ of $80 \%$ (v/v) ethanol. Soluble sugars were extracted by
Table 1 Components of decarboxylation in leaves of WT and MSC16 cucumber $\left(\mu \mathrm{mol} \mathrm{CO} \mathrm{Cm}^{-2} \mathrm{~s}^{-1}\right)$

\begin{tabular}{lcr}
\hline & WT & \multicolumn{1}{l}{ MSC16 } \\
\hline Respiration in the dark $\left(R_{\mathrm{D}}\right)$ & & \\
& & \\
& & \\
& & \\
Decarboxylation in the light & & \\
Total $(R)$ & $2.16 \pm 0.01$ & \\
Photorespiratory $\left(R_{\mathrm{P}}\right)$ & $1.91 \pm 0.14$ & $1.84 \pm 0.19$ \\
Respiratory $\left(R_{\mathrm{R}}\right)$ & $0.25 \pm 0.01$ & $1.61 \pm 0.18$ \\
Decarboxylation of primary photosynthates & $0.23 \pm 0.02$ \\
Total $\left(R_{\mathrm{A}}\right)$ & $1.86 \pm 0.12$ & $1.64 \pm 0.17$ \\
Photorespiratory $\left(R_{\mathrm{PA}}\right)$ & $1.68 \pm 0.12$ & $1.47 \pm 0.16$ \\
Respiratory $\left(R_{\mathrm{RA}}\right)$ & $0.18 \pm 0.01$ & $0.17 \pm 0.01$ \\
Decarboxylation of stored photosynthates & \\
Total $\left(R_{\mathrm{S}}\right)$ & $0.30 \pm 0.02$ & $0.20^{*} \pm 0.02$ \\
Photorespiratory $\left(R_{\mathrm{PS}}\right)$ & $0.23 \pm 0.02$ & $0.14 * \pm 0.02$ \\
Respiratory $\left(R_{\mathrm{RS}}\right)$ & $0.07 \pm 0.01$ & $0.05 \pm 0.01$ \\
\hline
\end{tabular}

Values are means from three replicates \pm SD

* Significant differences $(\alpha \leq 0.05)$

heating the samples $\left(37^{\circ} \mathrm{C}\right)$ for $2 \mathrm{~h}$. Homogenates were clarified by centrifugation at $10,000 \mathrm{~g}$ for $10 \mathrm{~min}$. The extractions were repeated twice and the combined extracts used for soluble sugar estimates, whereas pellet was analyzed for starch. Ethanol was evaporated and glucose and fructose were quantified enzymatically as described in Kunst et al. (1985a) and Beutler (1985), respectively. Concentrations of Suc were determined after degradation to Glc plus Fru. Pellets were resuspended in $3 \mathrm{ml}$ water and boiled for $3 \mathrm{~h}$ for starch content analyses. Amyloglucosidase was used to digest starch samples overnight. Released glucose was determined spectrophotometrically in glucose oxidaseperoxidase reaction (Kunst et al. 1985b). Pyruvate concentrations were assayed by method of Lamprecht and Hainz (1985). The concentrations of citrate and 2-oxoglutarate were measured enzymatically as described in Möllering (1985) and Brulina (1985), respectively. The concentration of nitrate was measured according to the method of Cataldo et al. (1975). Free $\mathrm{NH}_{4}{ }^{+}$concentration was assayed by Berthelot reaction (phenol hypochloride colorimetric method) as described in Husted et al. (2000). For amino acid extractions approx $1 \mathrm{~g}$ of FW of tissue was homogenized with $2 \mathrm{ml}$ of PCA. The homogenate was centrifuged at $10,000 \mathrm{~g}$ for $10 \mathrm{~min}$ and then neutralized by adding $\mathrm{K}_{2} \mathrm{CO}_{3}$. After centrifugation at $10,000 \mathrm{~g}$ for $10 \mathrm{~min}$ the supernatant was used for analysis. Total amino acid concentration was assayed by the colorimetric method of Rosen (1957). Individual amino acids were recognized as DABS derivatives by RP-HPLC (Chang et al. 1983). Protein content was measured according to the method of Bradford (1976), using bovine serum albumin (BSA) as the standard. 
Table 2 Amount of carbon fixed and rate of carbon fixation in leaves of WT and MSC16 cucumber after their 5- and 15-min exposure to ${ }^{14} \mathrm{CO}_{2}$
Values are means from 3 replicates $\pm \mathrm{SD}$

\begin{tabular}{lccc}
\hline & \multicolumn{2}{l}{$\begin{array}{l}\text { Amount of carbon fixed }\left(\mathrm{nmol} \mathrm{C} \mathrm{cm}^{-2}\right) \\
\text { Exposure to }{ }^{14} \mathrm{CO}_{2}\end{array}$} & $\begin{array}{l}\text { Rates of carbon fixation } \\
\left(\mu \mathrm{mol} \mathrm{C} \mathrm{m} \mathrm{s}^{-1}\right)\end{array}$ \\
\cline { 2 - 3 } & \multicolumn{2}{c}{$15 \mathrm{~min}$} & \\
\hline WT & & & \\
Solubles & $61.47 \pm 5.03$ & $201.13 \pm 10.37$ & $2.32 \pm 0.19$ \\
Starch & $90.38 \pm 3.69$ & $264.66 \pm 23.37$ & $2.90 \pm 0.39$ \\
Insolubles & $8.57 \pm 1.10$ & $19.14 \pm 1.01$ & $0.18 \pm 0.02$ \\
Total & $160.42 \pm 5.97$ & $484.93 \pm 29.37$ & $5.37 \pm 0.15$ \\
MSC16 & & & \\
Solubles & $83.54 \pm 0.38$ & $250.23 \pm 14.90$ & $2.78 \pm 0.25$ \\
Starch & $100.28 \pm 1.89$ & $302.57 \pm 13.64$ & $3.37 \pm 0.23$ \\
Insolubles & $8.72 \pm 2.47$ & $16.14 \pm 1.47$ & $0.12 \pm 0.05$ \\
Total & $192.55 \pm 0.96$ & $568.94 \pm 18.44$ & $6.37 \pm 0.09$ \\
\hline
\end{tabular}

\section{Determinations of enzymes activities}

Enzymes were extracted from frozen material (leaf tissue or mitochondrial fraction) stored at $-80^{\circ} \mathrm{C}$. Nitrate reductase (NR) maximal activity was measured as described in Reda and Kłobus (2006). Glutamine synthetase (GS) activity was measured according to Wallsgrove et al. (1979). Activities of the TCA cycle enzymes and PDC were measured using isolated mitochondria. Citrate synthase (CS) and aconitase activities were assayed in mitochondrial fractions according to Jenner et al. (2001), PDC activity was measured using the method of Budde et al. (1988), and the activity of fumarase was determined as described in Stitt (1984).

\section{Western-blot analysis}

Protein gel blot analyses were performed using isolated mitochondria or tissue extracts. The samples, $20 \mu \mathrm{g}$ protein per lane, were separated by SDS-PAGE (10\% polyacrylamide) according to a standard protocol. The polypeptides were electroblotted to a nitrocellulose membrane and probed with primary antibodies [Anti-GS (gift of Dr. C. Masclaux-Daubresse, INRA Versailles), anti-IDH (Agrisera, Vännäs, Sweden), anti- $\alpha$ subunit of PDC (gift of Dr. J. Miernyk; Luethy et al. 1995)] overnight at $4^{\circ} \mathrm{C}$. Antirabbit antibodies conjugated to horseradish peroxidase (Bio-Rad, Hercules, CA, USA) were used as secondary antibodies. Visualization was performed with a chemiluminescent reagent system. Protein amounts were determined by densitometry of the membranes using Quantity One 4.6.2 software (Bio-Rad).

Partitioning of fixed carbon into soluble sugars, and starch synthesis

The rates of carbon incorporation into starch and soluble compounds were determined from their labeling curves obtained by exposing leaves for different time periods to ${ }^{14} \mathrm{CO}_{2}$ in the light under steady-state photosynthesis as described in Pärnik et al. (1987). After the exposure leaves were killed in boiling $80 \%(\mathrm{v} / \mathrm{v})$ ethanol, extracted twice in boiling $80 \%$ ethanol, and once in boiling acidified $96 \%$ ethanol. The extracts were combined and concentrated. The radioactivity of soluble compounds was determined using a LS 100C liquid scintillation spectrometer (Beckman Coulter, Brea, CA, USA). From the values of radioactivity and of the specific radioactivity of ${ }^{14} \mathrm{CO}_{2}$ fed to leaves, the amounts of carbon incorporated into different compounds were calculated. To determine the radioactivity incorporated into starch, the material remaining after the extraction of soluble compounds was incubated in a solution of $\alpha$-amylase (Boehringer Ingelheim, Ingelheim, Germany; $200 \mathrm{mg}^{-1}$ (w/v) in sodium citrate buffer, $\mathrm{pH}$ 6.8) for $48 \mathrm{~h}$ at $35^{\circ} \mathrm{C}$, and the radioactivity released by hydrolysis was quantified. Bacterial decomposition was prevented by adding a drop of toluene in the incubations. Radioactivity of the final pellet remaining after the hydrolysis of starch (denominated as insolubles) was quantified using non-aqueous scintillation cocktails.

\section{Measurements of components of decarboxylation}

The components of decarboxylation in the light were determined using a radiogasometric method as described in Pärnik and Keerberg (2007).

Statistical analysis

All results presented are mean values \pm standard deviations, from $n$ ( $n=3-12)$ measurements taken from twoseven independent plant cultures. The significance of the results compared with the control was tested using the Student's $t$ test $(\alpha \leq 0.05)$. 
Fig. 1 The concentration of glucose (a), fructose (b), sucrose (c), and starch (d) in the leaf tissue of WT and MSC16 plants. Leaf samples were collected after $8 \mathrm{~h}$ of darkness (gray bars) or after $6 \mathrm{~h}$ of illumination (white bars). Values are means from 4-10 replicates \pm SD. Bars with different letters were significantly different at $\alpha \leq 0.05$
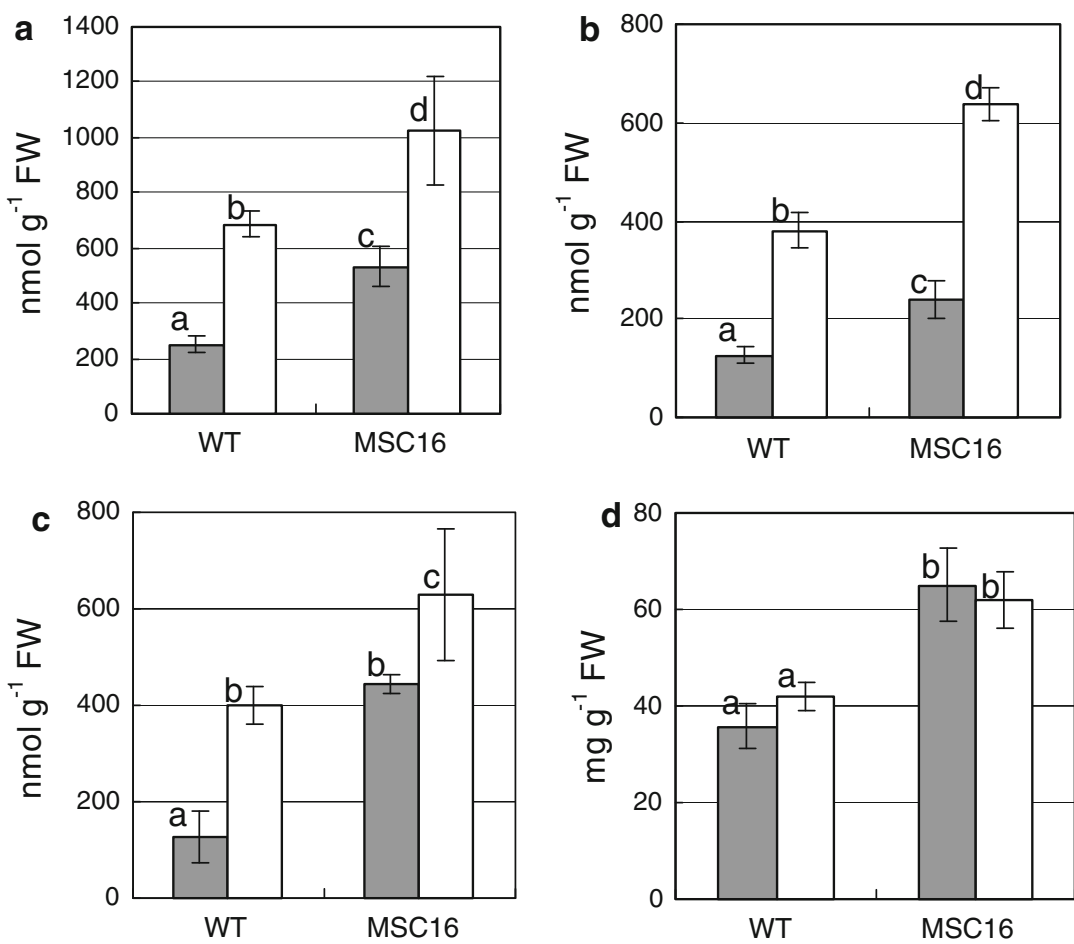

\section{Results}

In MSC16 plants leaf dark respiration rate $\left(R_{\mathrm{D}}\right)$ measured as $\mathrm{CO}_{2}$ evolution was about $20 \%$ lower as compared with WT plants (Table 1) but in the light the total decarboxylation $(R)$ was similar in MSC16 and WT plants (Table 1). Under light conditions the main process of $\mathrm{CO}_{2}$ evolution in both genotypes was photorespiration $\left(R_{\mathrm{P}}\right)$, about $90 \%$ of total decarboxylation in both WT and MSC16 plants. The prevailing substrates for decarboxylation were primary photosynthates (86-89\%, $R_{\mathrm{A}} / R$ ratio). In WT plants about $80 \%$ of stored photosynthates were consumed in photorespiratory decarboxylations $\left(R_{\mathrm{PS}} / R_{\mathrm{S}}\right.$ ratio). In MSC16 plants $R_{\mathrm{PS}}$ value was lower, about $70 \%$ of $R_{\mathrm{S}}$. By comparison of $R_{\mathrm{RS}}$ and $R_{\mathrm{D}}$ values it is possible to calculate light inhibition of respiration in both genotypes (Pärnik and Keerberg 2007). In both WT and MS16 plants, light suppressed the respiratory decarboxylation of stored photosynthates (the only component operative in the dark) in about $93 \%$. The total rate of respiration in the light $\left(R_{\mathrm{R}}\right.$ including respiratory decarboxylation of primary photosynthates) was about $75 \%$ lower than in the dark (Table 1).

We have compared the soluble sugar concentration in the leaves of WT and MSC16 plants after night period and during day. At the end of the 8-h dark period the concentrations of Glc, Fru, and Suc were higher in MSC16 leaves by 100,85 , and $250 \%$, respectively, as compared with WT plants (Fig. 1a-c). After $6 \mathrm{~h}$ of illumination the concentration of soluble sugars increased significantly both in WT and in MSC16 plants (Fig. 1a-c). Under light conditions sugar levels were 50-60\% higher in the leaves of MSC16 plants than WT plants (Fig. 1a-c).

To test the possibility that the differences in sugar concentration between WT and MSC16 leaves were due to the differences in photosynthetic carbon assimilation, we measured the rates of $\mathrm{CO}_{2}$ fixation in WT and MSC16 leaves. Dysfunction of mitochondria in MSC16 did not affect the $\mathrm{CO}_{2}$ assimilation (Table 2). After $5 \mathrm{~min}$ of exposure to ${ }^{14} \mathrm{CO}_{2}$, the amount of radioactive $\mathrm{C}$ incorporated into different fractions (soluble, starch, insolubles) was slightly higher in MSC16 plants. After additional 10 min feeding the differences between genotypes were more pronounced, with exception of the insolubles. The rates of carbon incorporation into soluble compounds and starch were 15-20\% higher in MSC16 plants than in WT plants. Cucumis sativus is a starch-accumulating plant (Ono et al. 1999), and 53\% of photosynthetically fixed carbon was incorporated into starch in both genotypes of cucumber (Table 2). The content of starch was higher in MSC16 plants after the dark period by about $80 \%$, but under light period only by about $45 \%$ as compared with WT plants (Fig. 1d). It is well documented that starch concentration increases in leaf tissue during day. We have also observed in cucumber leaves diurnal changes in starch concentration; after $9 \mathrm{~h}$ of light period the concentration of starch doubled in WT leaves and was higher in MSC16 leaves by about $40 \%$ as compared with the leaf tissues collected after the dark period (results not shown). 
Suppression of dark respiration by light can result in changes in concentration of TCA cycle intermediates. During night pyruvate is probably the main substrate entering the TCA cycle. Under darkness, pyruvate levels in the leaves of MSC16 plants were similar to those in WT leaves (Fig. 2a). Illumination resulted in a great increase (almost 3-times) in pyruvate concentration in WT leaves (Fig. 2a) probably indicating its lower utilization in TCA cycle but in MSC16 leaves pyruvate concentrations were not affected by the light conditions (Fig. 2a). Moreover, the activity and protein level of pyruvate dehydrogenase complex (PDC) in mitochondria of MSC16 plants were higher compared with WT mitochondria (about 100 and $40 \%$, respectively; Fig. 3a).
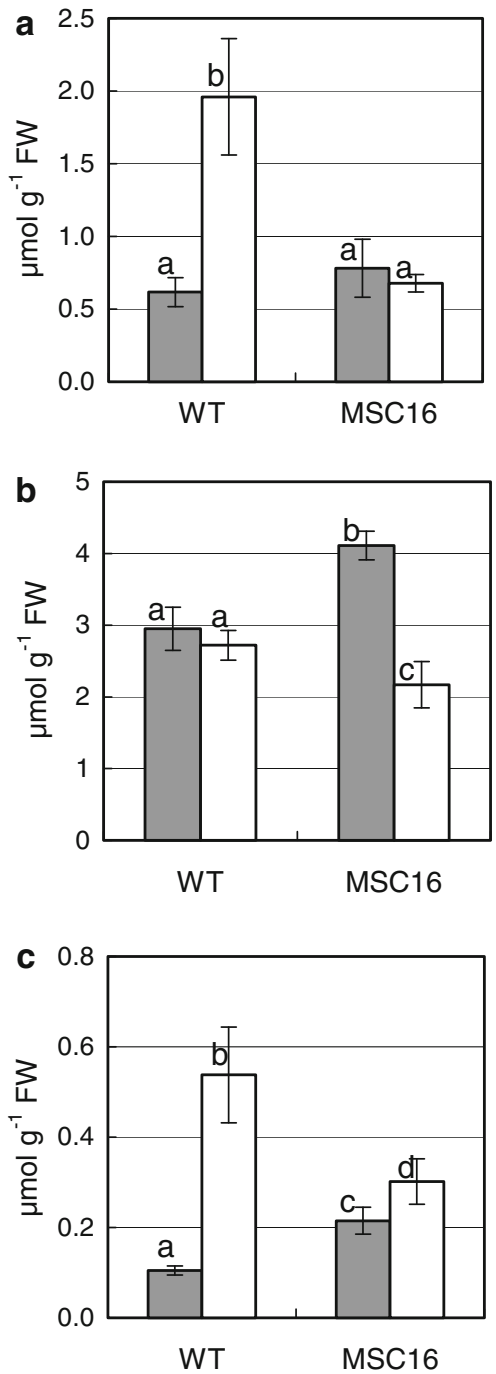

Fig. 2 The concentration of pyruvate (a), citrate (b), and 2-OG (c) in the leaf tissue of WT and MSC16 plants. Leaf samples were collected after $8 \mathrm{~h}$ of darkness (gray bars) or after $6 \mathrm{~h}$ of illumination (white bars). Values are means from 3-5 replicates \pm SD. Bars with different letters were significantly different at $\alpha \leq 0.05$
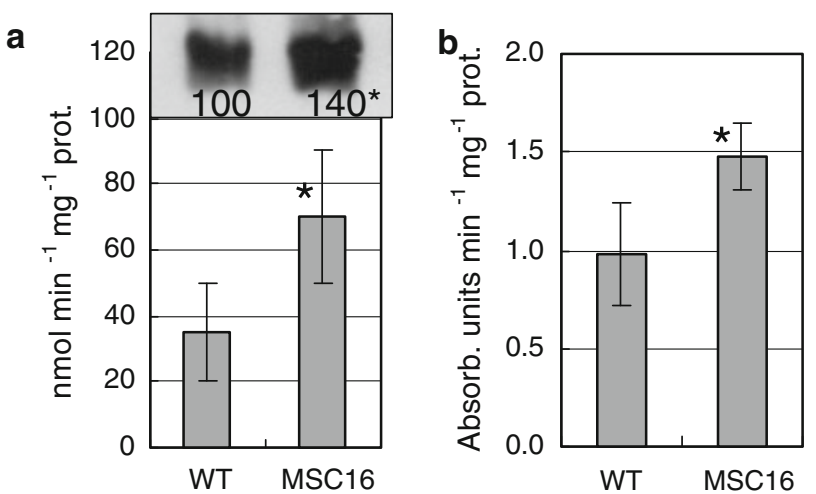

C
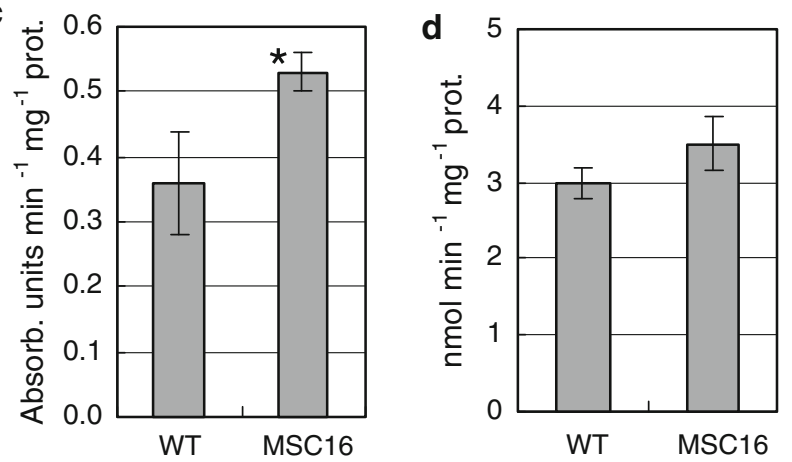

e

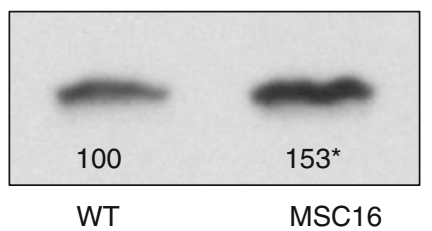

Fig. 3 The activity of pyruvate dehydrogenase complex (a) and PDC protein level (inset) in WT and MSC16 mitochondria. The activity of citrate synthase (b), aconitase (c) and fumarase (d) in WT and MSC16 mitochondria. Protein level of mitochondrial IDH (e). Mitochondria were isolated from cucumber WT or MSC16 leaves collected after $8 \mathrm{~h}$ of darkness. Signal intensities of bands corresponding to the PDC or IDH were estimated using Quantity One 4.6.2 software after correcting for background. Results are expressed relative to control; the amount of protein (PDC or IDH) in WT mitochondria is set as 100. Representative results are shown. Values are means from 35 replicates \pm SD. *Significant differences $(\alpha \leq 0.05)$

In WT plants under darkness, when the TCA cycle is fully operative, the concentration of 2-OG was almost 30-times lower than citrate (Fig. 2b, c). In the light the concentration of citrate in WT leaves remained at the same level (Fig. 2b), but 2-OG concentration increased about fivefold compared with that in darkness (Fig. 2c). In MSC16 plants under darkness the leaf concentrations of 2-OG and citrate were higher than in WT leaves (100 and $40 \%$, respectively; Fig. 2b, c). Effect of the light on TCAconcentration of cycle intermediates is different in MSC16 as compared with WT plants. In the light in MSC16 leaves 
the 2-OG level increased only by about $40 \%$ compared with that in the dark (Fig. 2c), but citrate level decreased by about $50 \%$ (Fig. 2b) compared with dark conditions.

Activities of TCA cycle enzymes were estimated in mitochondria isolated from WT and MSC16 leaves. Diurnal changes in the activities of TCA cycle enzymes and PDC were not found (results not shown), but it should be noted that these activities were measured in vitro under optimal conditions and might not reflect of the effective activity in vivo. During the night period in MSC16 mitochondria, the activities of citrate synthase (CS) and aconitase were 50 and $45 \%$, respectively, higher than those of WT mitochondria (Fig. 3b, c). The protein level of mitochondrial IDH was about $50 \%$ higher in mitochondria from MSC16 plants as compared with WT mitochondria (Fig. 3e). Exceptionally, the activity of fumarase was similar in MSC16 and WT plants (Fig. 3d).

The difference in concentrations of TCA-cycle intermediates between WT and MSC16 leaves could result from restricted availability of substrates for mitochondrial respiration (which was not the case in MSC16 plants) or altered utilization. In the light the concentrations of TCA intermediates are tightly connected with nitrate assimilation (Hanning and Heldt 1993). The concentration of nitrate in light was lower in MSC16 leaves by about $25 \%$ (Fig. 4a), and a significant decrease (about 45\%) in NR activity was observed (Fig. 4b). Ammonium concentrations were about 50\% higher in MSC16 leaf compared with WT (Fig. 4c), but GS activities and protein levels were unchanged (Fig. 4d, e).

The total concentration of free amino acids was similar in WT and MSC16 leaves (Fig. 5, inset), but HPLC analysis revealed differences in the levels of individual amino acids (Fig. 5). In MSC16 leaves, increases in Glu, Arg, and Ala (35, 250, and 95\%, respectively) and a decrease in Asp (by $45 \%$ ) were found (Fig. 5).

\section{Discussion}

The aim of this work is to characterize the processes in cucumber leaves that lead to a modified $\mathrm{C} / \mathrm{N}$ homeostasis in response to mitochondrial genome rearrangements. Contrary to well-characterized Complex I mutants of tobacco (Pla et al. 1995; Sabar et al. 2000), maize (Marienfeldt and Newton 1994; Karpova et al. 2002), and Arabidopsis (Lee et al. 2002; Perales et al. 2005; Nakagawa and Sakurai 2006; Falcon de Longevialle et al. 2007; Meyer et al. 2009) the precise nature of MSC16 mutation remains unknown (Bartoszewski et al. 2004). However, we have found that rearrangement of mitochondrial genome in the MSC16 plants is associated with differences in TCA cycle operation and $\mathrm{N}$ assimilation.
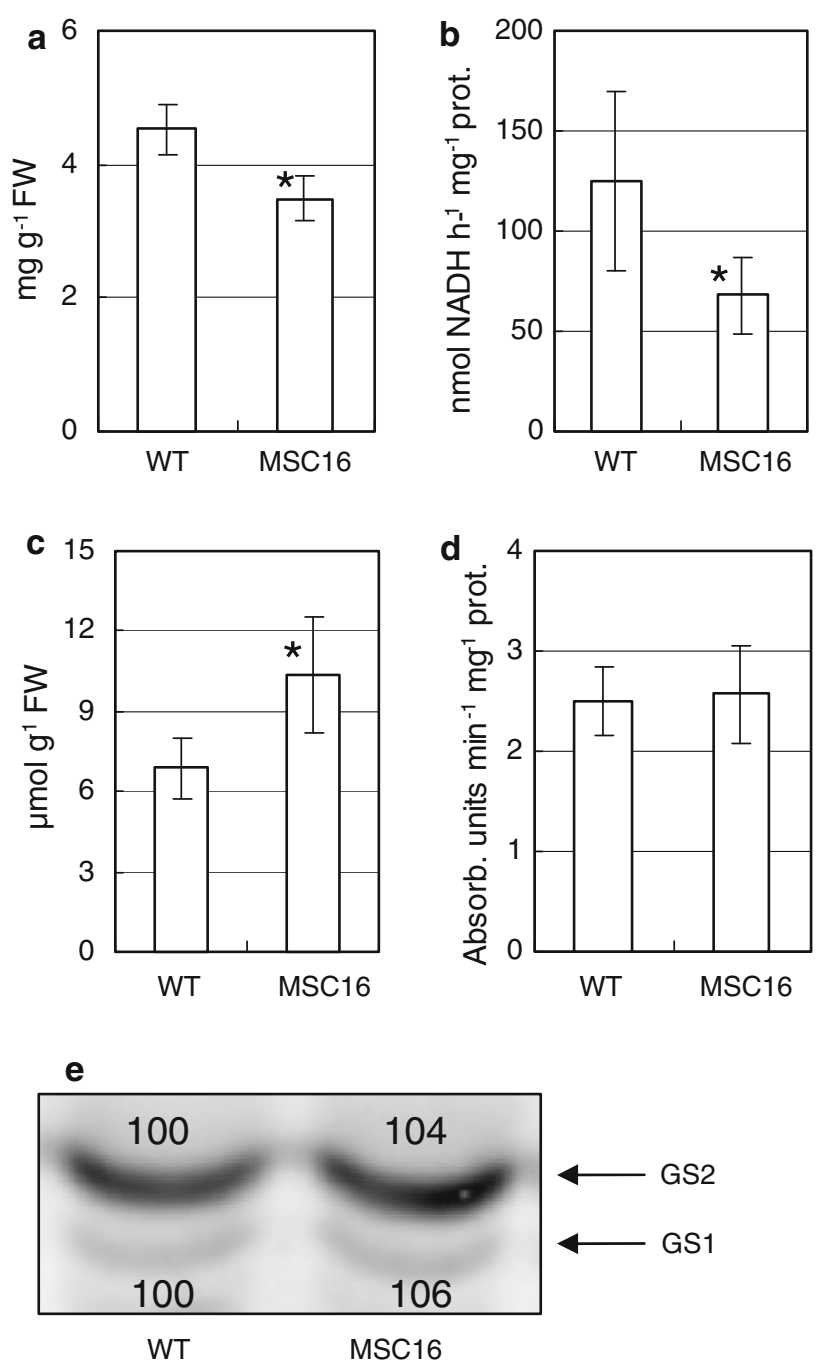

Fig. 4 Nitrate concentration (a), maximal nitrate reductase activity (b), ammonium concentration (c), the activity of glutamine synthetase (d), and GS1 and GS2 protein levels (e) in illuminated WT and MSC16 leaves. Signal intensities of bands corresponding to the GS1 and GS2 were estimated using Quantity One 4.6.2 software after correcting for background. Results are expressed relative to control; the amount of protein (GS1 or GS2) in WT mitochondria is set as 100 . Representative results are shown. Values are means from 3-10 replicates \pm SD. * Significant differences $(\alpha \leq 0.05)$

Mitochondrial genome rearrangement in MSC16 plants and mutation in CMS II tobacco plants have a negative effect on plant growth (Malepszy et al. 1996; Noctor et al. 2004) possibly through perturbation of chloroplast/mitochondrial interactions. However, the mechanisms that underlie modified $\mathrm{C} / \mathrm{N}$ homeostasis likely differ between the two mutants. The effects of Complex I dysfunction on $\mathrm{C}$ and $\mathrm{N}$ metabolism were previously studied in the tobacco CMSII mitochondrial mutant (Dutilleul et al. 2005). In CMSII plants the lack of Complex I is compensated for by increased engagement of external NADH dehydrogenase (Sabar et al. 2000) and enhanced COX activity (Priault 
Fig. 5 The concentration of total free amino acids (inset) and individual amino acids in illuminated leaves of WT and MSC16 plants. Values are means from 4-12 replicates \pm SD. $*$ Significant differences $(\alpha \leq 0.05)$

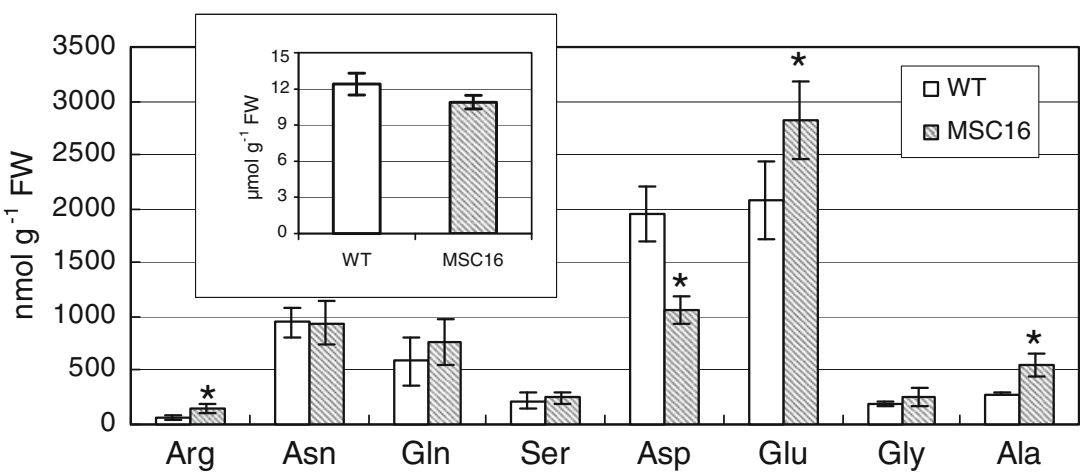

et al. 2007). In MSC16 plants, decrease in activity of Complex I (by 20\%) is not associated with altered activity of the cytochrome pathway (Juszczuk et al. 2007). The mitochondrial compensating mechanisms shown in the tobacco (Sabar et al. 2000; Priault et al. 2007) result (in contrast to MSC16 cucumber) in much higher concentrations of adenylates and pyridine nucleotides in CMSII plants than in tobacco WT (Dutilleul et al. 2005; Szal et al. 2008), and no energy deficit occurs in those plants as was observed in MSC16 (Juszczuk et al. 2007; Szal et al. 2008). In Arabidopsis ndufs 4 plants lack of Complex I is associated with lower mitochondrial ATP synthesis and in consequence with decreased ATP level during the night (Meyer et al. 2009). However, during day the increase in ATP pool was observed and was due to the higher rate of substrate-level phosphorylation (Meyer et al. 2009). On the contrary, in MSC16 plants energy deficit was even more pronounced during day than during darkness (Juszczuk et al. 2007).

In our previous work (Juszczuk et al. 2007) we observed decreased ATP levels in MSC16 leaves, but dark respiration rates were unchanged compared with WT leaves. The plants that were used in our previous experiments for determining leaf respiration and photosynthetic activity were grown under high light conditions: PAR about $400 \mu \mathrm{mol} \mathrm{s}{ }^{-1} \mathrm{~m}^{-2}$ (growth conditions, Juszczuk et al. 2007). Recently we reported that MSC16 plants have an altered response to stress conditions (Szal et al. 2009), leading us to repeat estimations of $R_{\mathrm{D}}$ and light respiration using the plants grown at medium light intensity (PAR about $200 \mu \mathrm{mol} \mathrm{s}{ }^{-1} \mathrm{~m}^{-2}$ ) similar to that used for measuring metabolite concentration and enzyme activities. The perturbations in functioning of the TCA cycle in the dark in MSC16 plants were manifested by a lower decarboxylation rate $\left(R_{\mathrm{D}}\right)$ (Table 1) and by increased concentration of intermediates of the TCA cycle (Fig. 2b, c). Florez-Sarasa et al. (2009) did not find a difference in the dark respiration rate between WT and MSC16 measured as $\mathrm{O}_{2}$ uptake. Oxygen uptake measurements indicate mtETC capacity (Florez-Sarasa et al. 2009) whereas the rate of $\mathrm{CO}_{2}$ release reflects PDC and TCA-cycle decarboxylating activities. The rise in organic acid concentrations in the dark in MSC16 plants is not due to restricted availability of respiratory substrates as the concentrations of soluble sugars was higher in MSC16 plants than in WT plants (Fig. 1a-c). Also, the increased activity and/or protein level of the PDC (Fig. 3a), CS (Fig. 3b), aconitase (Fig. 3c), and IDH (Fig. 3e) in MSC16 mitochondria suggests that the limiting step in TCA cycle activity is between 2-OG and malate. The role of individual enzymes of TCA cycle on whole cell metabolism has been studied in detail (Nunes-Nesi et al. 2008 and references therein). It was suggested that 2-OG dehydrogenase complex (OGDC) may have a role in the regulation of TCA cycle activity (Araújo et al. 2008). The activity of OGDC is sensitive to the redox state of mitochondria (Balmer et al. 2004), and it has been shown that inhibition of this enzyme complex results in a reduction of respiration rate coupled to the changes in the TCA cycle intermediates and amino acids levels (Araújo et al. 2008). Previously it has been suggested that the decrease in 2-OG is the common response to Complex I deficiency, and could play a key role in the signaling of mtETC dysfunction (Garmier et al. 2008). Decreased levels of 2-OG were found in response to rotenone treatment of Arabidopsis cell cultures (Garmier et al. 2008) and in tobacco plants lacking mitochondrial Complex I (Dutilleul et al. 2005). In MSC16 plants the small decrease in Complex I activity is associated with different effect on 2-OG concentration in the dark and in the light (Fig. 2c). We observed the increased 2-OG concentration in darkened leaves of MSC16 plants, but under light conditions 2-OG levels decreased compared with WT (Fig. 2c). In the light, TCA-cycle intermediates are exported from the mitochondria and used for anabolic reactions (Hanning and Heldt 1993). Recently, it has been reported that under light conditions the enzymes of TCA cycle operate in non-cyclic reactions and CS is a rate-limiting step in citrate synthesis (Tcherkez et al. 2009). In Xanthium strumarium leaves stored substrate remobilization providing 2-OG that was coupled to Glu synthesis (Tcherkez et al. 2009). Moreover, 
it has been proven that day/night cycle was essential for $\mathrm{N}$ assimilation (Gauthier et al. 2010). However, it should be pointed that in our experiment the activity of CS measured in in vitro conditions was higher as compared with aconitase activity (Fig. 3). The combination of ammonium with 2-OG in the reaction catalyzed by GOGAT would result in increased Glu levels (Fig. 5) and simultaneously in decreased levels of the organic acids 2-OG and citrate in MSC16 plants (Fig. 2b, c).

In the dark the decarboxylation of pyruvate (by PDC) and the TCA cycle are mainly responsible for $\mathrm{CO}_{2}$ production. The higher $\mathrm{NH}_{4}{ }^{+}$in MSC16 could theoretically activate PDC kinase and thereby inactivate PDC (TovarMéndez et al. 2003). However, low ATP and mitochondrial NADH (Szal et al. 2008) will counteract the inhibiting effect of $\mathrm{NH}_{4}{ }^{+}$, and we have not seen dark inhibition of the PDC in MSC16 plants, nor observed increased pyruvate levels (Fig. 2a). Therefore, we conclude that decreased decarboxylation rate in the dark $\left(R_{\mathrm{D}}\right.$, Table 1$)$ was rather the effect of perturbation in TCA cycle activity. In the light the inactivation of PDC leads to increased pyruvate levels in WT leaves, but not in MSC16 leaves (Fig. 2a). The basis for these contrasting observations remains unclear. First, pyruvate might be intensively used in $\mathrm{NH}_{4}{ }^{+}$detoxification in MSC16 plants. The combination of ammonium with pyruvate catalyzed by cytosolic AAT might lead to the observed decreased level of this metabolite (Fig. 2a) and simultaneously to the increased level of Ala (Fig. 5). In css 1 Arabidopsis mutant the accumulation of Ala was also found (Nakagawa and Sakurai 2006). Second, the flow of acetyl-CoA into the TCA cycle might be enhanced. Alternatively it has been documented that fatty acid synthesis is a key sink for acetyl-CoA (Tcherkez et al. 2005). In the MSC16 plants, enhanced utilization of acetyl-CoA for fatty acid synthesis might be manifest as the increased level of oleic acid found in this tissue (S. Malepszy, personal communication).

The altered activities of the TCA cycle enzymes can have different effects on photosynthesis. A decreased photosynthetic rate was found in plants with decreased fumarase activity (Nunes-Nesi et al. 2007). In contrast, an increase in photosynthesis was observed in mutants with decreased expression of aconitase (Carrari et al. 2003) or MDH (Nunes-Nesi et al. 2005). However, reduced activities of succinyl-CoA ligase (Studart-Guimarães et al. 2007), mitochondrial IDH (Lemaitre et al. 2007), or CS (Sienkiewicz-Porzucek et al. 2008) had no effect on photosynthesis. Lack of Complex I activity in tobacco CMS II mutant resulted in lower photosynthesis rate (Dutilleul et al. 2003; Priault et al. 2007) and in decreased Glu, Fru, and starch concentrations (Dutilleul et al. 2005). Cucumber MSC16 is heteroplasmic line and has a phenotype similar to maize NSC2 mutant: pale green stripes or yellowish spots were observed, respectively, in maize and cucumber mutants (Marienfeldt and Newton 1994; Malepszy et al. 1996). The pale green areas in NSC2 maize contain chloroplasts with lower amount of thylakoid membranes (Roussell et al. 1991). Moreover, in defective sectors lower $\mathrm{CO}_{2}$ fixation and decreased level of starch were also found (Roussell et al. 1991). On the contrary, the altered mitochondrial activity in MSC16 plants did not affect chloroplast structure (Malepszy et al. 1996) and photosynthetic $C$ assimilation rate (Table 2); however, the chloroplastidial ATP pool was decreased (Szal et al. 2008). In MSC16 plants the decreased $R_{\mathrm{D}}$ and $R_{\mathrm{PS}}$ values might have caused the increased levels of soluble sugars and starch (Fig. 1). In cucumber plants the transported sugar is stachyose (Miao et al. 2007), but increased level of sugars in leaves was not due to restricted transport to roots (results not shown).

The increase in ammonium concentration in MSC16 leaves (Fig. 4c) was not due to the photorespiratory activity which was lower in mutated line (Table 1). Rearrangements of mitochondrial genome in MSC16 plants (Juszczuk et al. 2007; Juszczuk and Rychter 2009) is associated with perturbation in cellular redox state; the increased cytosolic NADH concentration in MSC16 cells was observed (Szal et al. 2008). We suggest that altered nitrogen assimilation rate is the consequence of this situation. The reduction of $\mathrm{NO}_{3}{ }^{-}$to $\mathrm{NO}_{2}{ }^{-}$in the cytosol is limited mainly by the availability of reductants (Kaiser et al. 2000). Therefore, the increased cytosolic NADH/NAD ratio (Szal et al. 2008) could promote $\mathrm{NO}_{3}{ }^{-}$reduction in MSC16 leaves. The NADH availability was also a critical factor influencing the increased nitrate assimilation rate in CMS II tobacco cells (Dutilleul et al. 2005). Decreased NR activity in MSC16 tissues (Fig. 4b) could prevent harmful nitrite accumulation. Nitrate uptake by roots and transport from roots to shoots was not limited in MSC16 plants, as the concentration of $\mathrm{NO}_{3}{ }^{-}$in xylem soap was similar in both lines, and root $\mathrm{NO}_{3}{ }^{-}$content is similar in MSC16 and WT plants (results not shown). Contrary to CMSII and css 1 mutants lacking Complex I where the increase of total free amino acids pools were found (Dutilleul et al. 2005; Nakagawa and Sakurai 2006) the leaf amino acids pool in MSC16 plants was unchanged (Fig. 5, inset) Also, we did not observe increased concentrations of the $\mathrm{N}$-rich amino acids Gln or Asn in MSC16 leaves (Fig. 5), which indicates that the C-skeleton availability for amino acid synthesis was not limiting. The only amino acid with high $\mathrm{N}: \mathrm{C}$ ratio which accumulates in MSC16 cucumber leaves is Arg (Fig. 5), and increased Arg content has previously been reported as a common response to mitochondrial Complex I impairment (Dutilleul et al. 2005; Garmier et al. 2008). Levels of Arg were increased in cucumber tissues in response to the increasing $\mathrm{NH}_{4}{ }^{+}$supply indicating the important role of 
this amino acid in the ammonium detoxification (Roosta and Schjoerring 2007).

In summary, the lowered Complex I and internal rotenone-insensitive NADH dehydrogenase activities (Juszczuk et al. 2007; Juszczuk and Rychter 2009) resulting in decreased capacity for NADH oxidation in mitochondrial matrix are associated with perturbation of TCA cycle operation. The genes encoding the TCA cycle enzymes are nuclear encoded; therefore, the changes in TCA activity must be secondary effects and reflect retrograde mitochondrion-nucleus communication. Inhibition of TCA cycle activity has a different influence on leaf cell metabolism under dark and light conditions. In the dark the decreased respiration rate (Table 1) results in lowered ATP production in MSC16 plants (Juszczuk et al. 2007). In the light the main basis for changes in $\mathrm{C} / \mathrm{N}$ metabolism between WT and MSC16 plants is the increased cytosolic $\mathrm{NADH}$ concentration in MSC16 plants resulting in enhanced nitrate assimilation coupled with increased utilization of 2-OG and citrate.

Acknowledgments We are grateful to Dr. Jan Miernyk (University of Missouri) for critical reading of the manuscript. We thank Dr. Katarzyna Winiarska (Faculty of Biology, University of Warsaw) for amino acid estimations. This work was supported by: Polish Ministry of Scientific Research and Information Technology (MNiI) grant no 2 PO4C 09927 given to A.M.R; grant of the Estonian Science Foundation (project 4173); and through Faculty of Biology, University of Warsaw intramural grants given to B.Sz.

Open Access This article is distributed under the terms of the Creative Commons Attribution Noncommercial License which permits any noncommercial use, distribution, and reproduction in any medium, provided the original author(s) and source are credited.

\section{References}

Araújo WL, Nunes-Nesi A, Trenkamp S, Bunik VI, Fernie AR (2008) Inhibition of 2-oxoglutarate dehydrogenase in potato tuber suggests the enzyme is limiting for respiration and confirms its importance in nitrogen assimilation. Plant Physiol 148: 1782-1796

Balmer Y, Vensel WH, Tanaka CK, Hurkman WJ, Gelhaye E, Rouhier N, Jacquot JP, Manieri W, Schürmann P, Droux M, Buchanan B (2004) Thioredoxin links redox to the regulation of fundamental processes of plant mitochondria. Proc Natl Acad Sci USA 101:2642-2647

Bartoszewski G, Malepszy S, Havey MJ (2004) Mosaic (MSC) cucumber regenerated from independent cell cultures possess different mitochondrial rearrangements. Curr Genet 45:45-53

Beutler HO (1985) D-fructose. In: Bergmayer HU, Bergmayer J, Graß1 M (eds) Methods in enzymatic analysis. Metabolites 1: carbohydrates, vol VI, 3rd edn. Verlag Chemie, Weinheim, pp 321-327

Bradford MM (1976) A rapid and sensitive method for quantification of microgram quantities of protein utilizing the principle of protein-dye binding. Anal Biochem 72:248-254
Brulina A (1985) 2-oxoglutarate. In: Bergmayer HU, Bergmayer J, Graß1 M (eds) Methods in enzymatic analysis. Metabolites 2: triand di-carboxylic acids, purines, pyrimidines and derivates, coenzymes, inorganic compounds, vol VII, 3rd edn. Verlag Chemie, Weinheim, pp 20-24

Budde RJA, Fang TK, Randall DD (1988) Regulation of the phosphorylation of mitochondrial pyruvae dehydrogenase complex in situ. Effects of respiratory substrates and calcium. Plant Physiol 88:1031-1036

Bykova NV, Keerberg O, Pärnik T, Bauwe H, Gardeström P (2005) Interaction between photorespiration and respiration in transgenic plants with antisense reduction in glycine decarboxylase. Planta 222:130-140

Carrari F, Nunes-Nesi A, Gibon Y, Lytovchenko A, Loureiro ME, Fernie AR (2003) Reduced expression of aconitase results in an enhanced rate of photosynthesis and marked shifts in carbon partitioning in illuminated leaves of wild species tomato. Plant Physiol 133:1322-1335

Cataldo DA, Haroon M, Schrader LE, Youngs VL (1975) Rapid colorimetric determination of nitrate in plant-tissue by nitration of salicylic-acid. Commun Soil Sci Plant Anal 6:71-80

Chang JY, Knecht R, Braun DG (1983) Amino acid analysis in the picomole range by precolumn derivatization and high-performance liquid chromatography. Methods Enzymol 91:41-48

Dutilleul C, Driscoll S, Cornic G, de Paepe R, Foyer C, Noctor G (2003) Functional mitochondrial complex $\mathrm{I}$ is required by tobacco leaves for optimal photosynthetic performance in photorespiratory conditions and during transients. Plant Physiol 131:264-275

Dutilleul C, Lelerge C, Prioul JL, De Paepe R, Foyer CH, Noctor G (2005) Mitochondria-driven changes in leaf NAD status exert a crucial influence on the control of nitrate assimilation and the integration of carbon and nitrogen metabolism. Plant Physiol 139:64-78

Falcon de Longevialle A, Meyer EH, Andrés C, Taylor NL, Lurin C, Millar AH, Small ID (2007) The pentatricopeptide repeat gene OTP43 is required for trans-splicing of the mitochondrial nadl intron 1 in Arabidopsis thaliana. Plant Cell 19:3256-3265

Florez-Sarasa I, Ostaszewska M, Galle A, Flexas J, Rychter AM, Ribas-Carbo M (2009) Changes of alternative oxidase activity, capacity and protein content in leaves of Cucumis sativus wildtype and MSC16 mutant grown under different light intensities. Physiol Plant 137:419-426

Gardeström P, Igamberdiev AU, Raghavendra AS (2002) Mitochondrial functions in the light and significance to carbon-nitrogen interactions. In: Foyer $\mathrm{CH}$, Noctor $\mathrm{G}$ (eds) Photosynthetic nitrogen assimilation and associated carbon and respiratory metabolism. Advances in Photosynthesis, vol 12. Kluwer, Dordrecht, pp 151-172

Garmier M, Carroll AJ, Delannoy E, Vallet C, Day DA, Small ID, Millar AH (2008) Complex I dysfunction redirects cellular and mitochondrial metabolism in Arabidopsis. Plant Physiol 148:1324-1341

Gauthier PPG, Bligny R, Gout E, Mahé A, Nogués S, Hodges M, Tcherkez GGB (2010) In folio isotopic tracing demonstrates that nitrogen assimilation into glutamate is mostly independent from current $\mathrm{CO}_{2}$ assimilation in illuminated leaves of Brassica napus. New Phytol 185:988-999

Hanning I, Heldt HW (1993) On the function of mitochondrial metabolism during photosynthesis in spinach (Spinacia oleracea L.) leaves: partitioning between respiration and export of redox equivalents and precursors for nitrate assimilation products. Plant Physiol 103:1147-1154

Hurry V, Igamberdiev AU, Keerberg O, Pärnik T, Atkin OK, ZaragozaCostells J, Gardeström P (2005) Respiration in photosynthetic 
cells. In: Lambers H, Ribas-Carbo M (eds) Plant respiration from cell to ecosystem. Springer, Dordrecht, pp 43-61

Husted S, Hebbern CA, Mattsson M, Schjoerring JK (2000) A critical experimental evaluation of methods for determination of $\mathrm{NH}_{4}{ }^{+}$ in plant tissue, xylem sap and apoplastic fluid. Physiol Plant 109:167-179

Igamberdiev AU, Chen T, Gardeström P (2006) Function of mitochondria during the transition from low light to high light. A study with barley (Hordeum vulgare) protoplasts incubated with oligomycin and rotenone. Planta 224:196-204

Jenner HL, Winning BM, Millar AH, Tomlinson KL, Leaver CJ, Hill SA (2001) NAD malic enzyme and the control of carbohydrate metabolism in potato tubers. Plant Physiol 126:1139-1149

Juszczuk IM, Rychter AM (2009) BN-PAGE analysis of the respiratory chain complexes in mitochondria of cucumber MSC16 mutant. Plant Physiol Biochem 47:397-406

Juszczuk IM, Flexas J, Szal B, Dąbrowska Z, Ribas-Carbo M, Rychter AM (2007) Effect of mitochondrial genome rearrangement on respiratory activity, photosynthesis, photorespiration and energy status of MSC16 cucumber (Cucumis sativus) mutant. Physiol Plant 131:527-541

Kaiser WM, Kandlbinder A, Stoimenova M, Glaab J (2000) Discrepancy between nitrate reduction rates in intact leaves and nitrate reductase activity in leaf extracts: what limits nitrate reduction in situ. Planta 210:801-807

Karpova OV, Kuzmin EV, Elthon TE, Newton KJ (2002) Differential expression of alternative oxidase genes in maize mitochondrial mutants. Plant Cell 14:3271-3284

Krömer S (1995) Respiration during photosynthesis. Annu Rev Plant Physiol Plant Mol Biol 46:45-70

Kunst A, Draeger B, Ziegenhorn J (1985a) UV methods with heksokinase and glucose-6-phosphate dehydrogenase. In: Bergmayer HU, Bergmayer J, Graß1 M (eds) Methods in enzymatic analysis. Metabolites 1: carbohydrates, vol VI, 3rd edn. Verlag chemie, Weinheim, pp 163-172

Kunst A, Draeger B, Ziegenhorn J (1985b) Colorimertic methods with glucose oxidase and peroxidase. In: Bergmayer HU, Bergmayer J, Graß1 M (eds) Methods in enzymatic analysis. Metabolites 1: carbohydrates, vol VI, 3rd edn. Verlag Chemie, Weinheim, pp 178-185

Lamprecht W, Hainz F (1985) Pyruvate. In: Bergmayer HU, Bergmayer J, Graßl M (eds) Methods in enzymatic analysis. Metabolites 1: carbohydrates, vol VI, 3rd edn. Verlag Chemie, Weinheim, pp 570-577

Lancien M, Gadal P, Hodges M (2000) Enzyme redundancy and the importance of 2-OG in higher plant ammonium assimilation. Plant Physiol 123:817-824

Lee BH, Lee H, Xiong L, Zhu JK (2002) A mitochondrial complex I defect impairs cold-regulated nuclear gene expression. Plant Cell 14:1235-1251

Lemaitre T, Urbanczyk-Wochniak E, Flesch V, Bismuth E, Fernie AR, Hodges M (2007) NAD-dependent isocitrate dehydrogenase mutants of Arabidopsis suggest the enzyme is not limiting for nitrogen assimilation. Plant Physiol 144:1546-1558

Luethy MH, David NR, Elthon TE, Miernyk JA, Randall DD (1995) Characterization of a monoclonal antibody directed against the E1 $\alpha$ subunit of plant mitochondrial pyruvate dehydrogenase. J Plant Physiol 145:443-449

Malepszy S, Burza W, Śmiech M (1996) Characterization of a cucumber (Cucumis sativus L) somaclonal variation with paternal inheritance. J Appl Genet 37:65-78

Marienfeldt JR, Newton KJ (1994) The maize NCS2 abnormal growth mutant has a chimeric nad4-nad7 mitochondrial gene and is associated with reduced complex I function. Genetics 138:855-863
Meyer EH, Tomaz T, Carroll AJ, Estavillo G, Dellannoy E, Tanz SK, Small ID, Pogson BJ, Millar AH (2009) Remodeled respiration in ndfus 4 with low phosphorylation efficiency suppresses Arabidopsis germination and growth and alters control of metabolism at night. Plant Physiol 151:603-619

Miao M, Xu X, Chen X, Xue L, Cao B (2007) Cucumber carbohydrate metabolism and translocation under chilling night temperature. J Plant Physiol 164:621-628

Møller IM (2001) Plant mitochondria and oxidative stress: electron transport, NADPH turnover, and metabolism of reactive oxygen species. Annu Rev Plant Physiol Plant Mol Biol 52:561-591

Möllering H (1985) Citrate. In: Bergmayer HU, Bergmayer J, Graß1 M (eds) Methods in enzymatic analysis. Metabolites 2: tri- and di-carboxylic acids, purines, pyrimidines and derivates, coenzymes, inorganic compounds, vol VII, 3rd edn. Verlag Chemie, Weinheim, pp 2-12

Nakagawa N, Sakurai N (2006) A mutation in At-nMat1a, which encodes a nuclear gene having high similarity to group II intron maturase, causes impaired splicing of mitochondrial NAD4 transcript and altered carbon metabolism in Arabidopsis thaliana. Plant Cell Physiol 47:772-783

Noctor G, Dutilleul C, de Paepe R, Foyer CH (2004) Use of mitochondrial electron transport mutants to evaluate the effects of redox state on photosynthesis, stress tolerance and the integration of carbon/nitrogen metabolism. J Exp Bot 55:49-57

Noguchi K, Yosida K (2008) Interaction between photosynthesis and respiration in illuminated leaves. Mitochondrion 8:87-99

Nunes-Nesi A, Carrari F, Lytovchenko A, Smith AM, Loureiro ME, Ratcliffe RG, Sweetlove LJ, Fernie AR (2005) Enhanced photosynthetic performance and growth as a consequence of decreasing mitochondrial malate dehydrogenase activity in transgenic tomato plants. Plant Physiol 137:611-622

Nunes-Nesi A, Carrari F, Gibon Y, Sulpice R, Lytovchenko A, Fisahn J, Graham J, Ratcliffe G, Sweetlove LJ, Fernie AR (2007) Deficiency of mitochondrial fumarase activity in tomato plants impairs photosynthesis via an effect on stomatal function. Plant $\mathrm{J}$ 50:1093-1106

Nunes-Nesi A, Sulpice R, Gibon Y, Fernie AR (2008) The enigmatic contribution of mitochondrial function in photosynthesis. J Exp Bot 59:1675-1684

Ono K, Ishimaru K, Aoki N, Takahashi S, Ozawa K, Ohkawa Y, Ohsugi R (1999) Characterization of maize sucrose-phosphate synthase protein and its effect on carbon partitioning in transgenic rice plants. Plant Prod Sci 2:172-177

Pärnik T, Keerberg O (2007) Advanced radiogasometric method for the determination of the rates of photorespiratory and respiratory decarboxylations of primary and stored photosynthates under steady-state photosynthesis. Physiol Plant 129:34-44

Pärnik TR, Keerberg OF, Jürisma EJ (1987) Quick-operating exposition chamber for studying photosynthesis with ${ }^{14} \mathrm{CO}_{2}$. Sov Plant Physiol 34:676-683

Perales M, Eubel H, Heinemeyer J, Colaneri M, Zabaleta E, Braun HP (2005) Disruption of a nuclear gene encoding a mitochondrial gamma carbonic anhydrase reduces complex I and supercomplexes $\mathrm{I}+\mathrm{III}_{2}$ levels and alters mitochondrial physiology in Arabidopsis. J Mol Biol 350:263-277

Picault N, Hodges M, Palmieri L, Palmieri F (2004) The growing family of mitochondrial carriers in Arabidopsis. Trends Plant Sci 9:138-146

Pla M, Mathieu C, De Paepe R, Chetrit P, Vedel F (1995) Deletion of the last two exons of the mitochondrial nad7 gene results in lack of the NAD7 polypeptide in a Nicotiana sylvestris CMS mutant. Mol Gen Genet 248:79-88

Plaxton WC, Podestá FE (2006) The functional organization and control of plant respiration. Crit Rev Plant Sci 25:159-198 
Priault P, Vidal G, De Paepe R, Ribas-Carbo M (2007) Leaf age-related changes in respiratory pathways are dependent on complex I activity in Nicotiana sylvestris. Physiol Plant 129:152-162

Raghavendra AS, Padmasree K (2003) Beneficial interactions of mitochondrial metabolism with photosynthetic carbon assimilation. Trends Plant Sci 8:546-553

Rasmusson AG, Geisler DA, Møller IM (2008) The multiplicity of dehydrogenases in the electron transport chain of plant mitochondria. Mitochondrion 8:47-60

Reda M, Kłobus G (2006) Modifications of the activity of nitrate reductase from cucumber roots. Biol Plantarum 50:42-47

Roosta HR, Schjoerring JK (2007) Effects of ammonium toxicity on nitrogen metabolism and elemental profile of cucumber plants. J Plant Nutr 30:1933-1951

Rosen H (1957) A modified ninhydrin colorimetric analysis for amino acids. Arch Biochem Biophys 67:10-15

Roussell DL, Thompson DL, Pallardy SG, Miles D, Newton KJ (1991) Chloroplast structure and function is altered in the NCS2 maize mitochondrial mutant. Plant Physiol 96:232-238

Rychter AM, Mikulska M (1990) The relationship between phosphate status and cyanide-resistant respiration in bean roots. Physiol Plant 79:663-667

Sabar M, De Paepe R, de Kouchkovsky Y (2000) Complex I impairment, respiratory compensation and photosynthetic decrease in nuclear and mitochondrial male sterile mutants of Nicotiana sylvestris. Plant Physiol 124:1239-1249

Sienkiewicz-Porzucek A, Nunes-Nesi A, Sulpice R, Lisec J, Centeno DC, Carillo P, Leisse A, Urbanczyk-Wochniak E, Fernie AR (2008) Mild reductions in mitochondrial citrate synthase activity result in a compromised nitrate assimilation and reduced leaf pigmentation but have no effect on photosynthetic performance or growth. Plant Physiol 147:115-127
Stitt M (1984) Fumarase. In: Bergmayer HU, Bergmayer J, Graß1 M (eds) Methods in enzymatic analysis. Enzymes 2: esterases, glycosidases, lyases, ligases, vol IV, 3rd edn. Verlag Chemie, Weinheim, pp 359-362

Studart-Guimarães C, Fait A, Nunes-Nesi A, Carrari F, Usadel B, Fernie AR (2007) Reduced expression of succinyl CoA ligase can be compensated for by an upregulation of the c-aminobutyrate (GABA) shunt in illuminated tomato leaves. Plant Physiol 145:626-639

Szal B, Dąbrowska Z, Malmberg G, Gardeström P, Rychter AM (2008) Changes in energy status of leaf cells as the consequence of mitochondrial genome rearrangement. Planta 227:697-706

Szal B, Łukawska K, Zdolińska K, Rychter AM (2009) Chilling stress and mitochondrial genome rearrangement in the MSC16 cucumber mutant affect the alternative oxidase and antioxidant defense system to a similar extent. Physiol Plant 137:435-445

Tcherkez G, Cornic G, Bligny R, Gout E, Ghashghaie J (2005) In vivo respiratory metabolism of illuminated leaves. Plant Physiol 138:1596-1606

Tcherkez G, Mahé A, Gauthier P, Mauve C, Gout E, Bligny R, Cornic G, Hodges M (2009) In folio respiratory fluxomics revealed by ${ }^{13} \mathrm{C}$ isotopic labeling and $\mathrm{H} / \mathrm{D}$ isotope effects highlight the noncyclic nature of the tricarboxylic acid "cycle" in illuminated leaves. Plant Physiol 151:620-630

Tovar-Méndez A, Miernyk JA, Randall DD (2003) Regulation of pyruvate dehydrogenase complex activity in plant cells. Eur $\mathbf{J}$ Biochem 270:1043-1049

Wallsgrove RM, Lea PJ, Miflin BJ (1979) Distribution of the enzymes of nitrogen assimilation within the pea leaf cell. Plant Physiol 63:232-236 